\title{
A model for the evolution of high frequencies of males in an androdioecious plant based on a cross-compatibility advantage of males
}

\author{
CHRISTINE VASSILIADIS $\dagger$, MYRIAM VALERO*†, PIERRE SAUMITOU-LAPRADE $\dagger$ \\ \& BERNARD GODELLE $\bigsqcup^{1}$ \\ $\dagger$ Laboratoire de Génétique et Evolution des Populations Végétales, ESA-CNRS 8016, Bât SN2, Université de Lille 1, \\ F-59655 Villeneuve d'Ascq cedex, France and \$Laboratoire d’Evolution et Systématique des Végétaux, \\ Université Paris Sud, Orsay, France
}

\begin{abstract}
Lloyd's (1975) and Charlesworth \& Charlesworth's (1978) phenotypic selection models for the maintenance of androdioecy predict that males (female-sterile individuals) must have an advantage in fertility $(K)$ of at least two in order to invade a hermaphroditic population, and that their equilibrium frequency $\left(x_{\mathrm{eq}}=(K-2) / 2(K-1)\right)$ is always less than 0.5 . In this paper, we develop a model in which male fertility is frequency-dependent, a situation not investigated in the previous models, to explore the conditions under which a high frequency of males (i.e. more than $50 \%$ ) could be maintained at equilibrium. We demonstrate that a gametophytic self-incompatibility (GSI) locus linked to a nuclear sex determination locus can favour rare alleles through male function, by causing frequencydependent selection. Thus, the spread of a female-sterility allele in a hermaphroditic population may be induced. In contrast with the previous models, our model can explain male frequencies greater than $50 \%$ in a functionally androdioecious species, as long as there is (i) dominance of female-sterility at the sex locus, and (ii) a few alleles at the self-incompatibility locus, even if the advantage in fertility of male phenotype is lower than two.
\end{abstract}

Keywords: androdioecy, evolution, female-sterility, reproduction, self-incompatibility.

\section{Introduction}

The two symmetrical sexual dimorphisms: gynodioecy (co-occurrence of female with hermaphroditic plants) and androdioecy (males and hermaphrodites) are both encountered in Angiosperms. Gynodioecy is the second most common plant breeding system after hermaphroditism ( $7 \%$ and $72 \%$, respectively, see Delannay, 1978; Richards, 1997), whereas androdioecy is remarkably rare (Yampolsky \& Yampolsky, 1922; Charlesworth, 1984; Anderson \& Symon, 1989; Vassiliadis, 1999). Lloyd (1975) and Charlesworth \& Charlesworth (1978) developed phenotypic selection models (Lloyd, 1977) to understand the maintenance of these two sexual dimorphisms in the context of evolution towards dioecy. These authors demonstrated that unisexual plants cannot invade a hermaphroditic population unless they have an advantage in fertility $(K)$. Specifically, assuming

*Correspondence. E-mail: Myriam.Valero@univ-lille1.fr ${ }^{1}$ Present address: Laboratoire Génome, Populations, Interactions UMR CNS 500; case 063, F-34095 Montpellier cedex 05, France nuclear inheritance of sex and a large panmictic population, Lloyd (1975) and Charlesworth \& Charlesworth (1978) have demonstrated that unisexual plants must be at least twice as fit as hermaphrodites $(K \geq 2)$ and that their equilibrium frequency $(x)$ is always less than 0.5 :

$x=\frac{K \quad 2}{2\left(\begin{array}{ll}K & 1\end{array}\right)}$.

Under these assumptions, as the same conditions hold for both male and female morphs, these phenotypic selection models or compensation models cannot explain why gynodioecy is more frequent than androdioecy.

In a partially selfing hermaphroditic population, selective pressures for the spread of a unisexual mutant are no longer identical for male and female plants (Lloyd, 1975; Charlesworth \& Charlesworth, 1978; Charlesworth, 1984). Female plants (always outcrossed) may be favoured when selfed hermaphrodites suffer from inbreeding depression. On the other hand, in the case of a female-sterile mutant, the occurrence of selfing lowers male plant fertility as a result of the reduction in 
the number of available female gametes. Consequently, gynodioecy may be maintained even if female advantage in fitness is less than two. But for androdioecy to be maintained, the fertility advantage of males must be more than double that of hermaphrodites. This could explain the rarity of androdioecy compared with gynodioecy.

Another possible explanation of the greater frequency of gynodioecy in nature concerns sex determination in such species. In many known gynodioecious species, expression of the sexual phenotype is the result of an interaction between nuclear and cytoplasmic genes (Couvet et al., 1990), whereas in the only two wellstudied androdioecious species, sex inheritance appears to be nuclear. In Mercurialis annua there is one dominant gene for male phenotype (Pannell, 1997b); and in Datisca glomerata two recessive genes are involved (Wolf et al., 1997). Various models assuming a nucleo-cytoplasmic inheritance of sex (e.g. Lewis, 1941; Couvet et al., 1986; Frank, 1989) have demonstrated that conditions for the maintenance of gynodioecy are less restrictive compared with simple nuclear genetic determination. Moreover, these models established that female plants under some conditions can reach equilibrium frequencies greater than $50 \%$, particularly when stochastic factors influence the spatial distribution of sex-determining genes (Couvet et al., 1998). High female frequencies are indeed often observed in gynodioecious species (e.g. Dommée et al., 1983; Cuguen et al., 1994).

The existence of functional androdioecy (i.e. a species in which hermaphrodites have been proved to have effective male function) has been verified in only seven plant species so far (Oxalis suksdorfii, Ornduff, 1972; Datisca glomerata, Liston et al., 1990; Fritsch \& Rieseberg, 1992; Mercurialis annua, Pannell, 1997c,d; Fraxinus lanuginosa, Ishida \& Hiura, 1998; Schizopepon bryoniaefolius, Akimoto et al., 1999; Phillyrea angustifolia, Lepart \& Dommée, 1992; Vassiliadis et al. 2000; Fraxinus ornus, Dommée et al., 1999). Datisca glomerata and $M$. апnиa are characterized by a male advantage in fertility more than double that of hermaphrodites; they exhibit high outcrossing rates but are not selfincompatible, and male frequencies within populations are low $(<30 \%)$. In these species the maintenance of male individuals may be explicable according to Lloyd's (1975) and Charlesworth \& Charlesworth's (1978) models. Contrary to theoretical expectations, hermaphrodites of $S$. bryoniaefolius are highly endogamous. However, in this species, the outcrossing rate has been reported to vary with male frequency (Akimoto et al., 1999) and male fertility is thus frequency-dependent, a condition not considered in previous models.

In $P$. angustifolia, male frequencies are close to $50 \%$ in most of the populations that have been studied in southern France (review in Vassiliadis, 1999). This sex ratio could suggest a functional dioecy. However, in previous controlled-crosses experiments (Vassiliadis et al., 2000), we have shown that hermaphrodites did reproduce via their male function. Moreover, the estimated male advantage in siring success was only 1.93 compared with hermaphrodites. In this previous study, hermaphrodites were shown to be self-incompatible and crossing success between hermaphrodites to be more variable than between males and hermaphrodites, perhaps because of cross-incompatibility among hermaphrodites. The male fertility of hermaphrodites has also been examined in a natural population using paternity analysis (Vassiliadis, 1999), and is not close to zero: in $P$. angustifolia hermaphrodites are functional and not cryptic females.

In the present paper, we explore how self-incompatibility may interact with sex determination in an androdioecious species to favour the male plants and thus increase their frequency at equilibrium above that predicted by previous models. A model is developed in which a sex determination locus is completely genetically linked to a self-incompatibility locus. The influences of three key parameters are discussed: dominance vs. recessiveness of female-sterility alleles, male advantage in fertility $(K)$, and number of self-incompatibility alleles $(n)$.

\section{Model assumptions and parameters}

The model developed in this study considers one infinite population, with no pollen limitation, no overlapping generations, and no mutations. The initial population contains only hermaphroditic individuals (initial frequency of males $x=0$ ). The model considers a gametophytic self-incompatibility (GSI) system which involves one $S$-locus, with ' $n$ ' alleles: $S_{1}, S_{2}, \ldots, S_{n}$. Under such a system, $S_{i}$ pollen is compatible with any recipient sporophyte $S_{j} / S_{k}$ (with $j$ and $k \neq i$ ). In the initial population, there are $n(n-1) / 2$ different diploid genotypes which are all heterozygotes as a result of the incompatibility system (Wright, 1939). At equilibrium, these genotypes are at equal frequencies, because of the negative frequencydependent selection caused by self-incompatibility systems. Consequently, each $S_{i}$ allele is present at a frequency of $1 / n$ in the population (Wright, 1939).

Starting from this equilibrium situation for selfincompatibility alleles, a second nuclear locus, noted $A$, governing the sexual phenotype is introduced. Two alleles are possible at this locus. The allelic form $A_{\mathrm{m}}$ encodes for female-sterility (male phenotype) and $A_{\mathrm{h}}$ causes female-fertility (hermaphroditic phenotype). The two loci, $S$ (self-incompatibility) and $A$ (female-sterility), are in complete linkage disequilibrium. 
We examined two dominance relationships: femalesterility is either dominant over female-fertility $\left(A_{\mathrm{m}}>\right.$ $\left.A_{\mathrm{h}}\right)$ or recessive $\left(A_{\mathrm{m}}<A_{\mathrm{h}}\right)$. (Analysis for the recessive case is presented in the Appendix.)

In the dominant case, female-sterile individuals are heterozygotes and the female-sterility allele $A_{\mathrm{m}}$ is associated with only one self-incompatibility allele, $S_{1}$. All other self-incompatibility alleles $\left(S_{2} \ldots S_{n}\right)$ play the same role in the population for obvious reasons of symmetry. We will thus consider their frequencies to be identical.

Under these assumptions, in a population containing $n$ incompatibility alleles, each 'regular' pollen genotype (not associated with female-sterility) will be incompatible if its incompatibility allele corresponds to one of the two alleles of the hermaphrodite recipient; these are different from each other and are both different from $S_{1}$ [probability $=2 /(n-1)]$. Because all non-male genotypes are present at the same frequency, all other 'regular' pollen grains are thus compatible with a probability of $1-(2 /(n-1))$ or $(n-3) /(n-1)$ (see

Table 1 Characteristics of crosses and progeny in the dominant model $\left(A_{\mathrm{m}}>A_{\mathrm{h}}\right)$ : only one 'male' haplotype is found $\left(S_{1} A_{\mathrm{m}}\right)$ in the population that contains ' $n$ ' incompatibility alleles

(a) Genotypes and associated phenotypes, relative male fertility and frequencies of individuals (there must be at least three self-incompatibility alleles)

\begin{tabular}{lccc}
\hline Genotype & $\begin{array}{c}\text { Sexual } \\
\text { phenotype }\end{array}$ & $\begin{array}{c}\text { Relative } \\
\text { male fertility }\end{array}$ & Frequency \\
\hline $\begin{array}{l}S_{1} A_{\mathrm{m}} / S_{i} A_{\mathrm{h}} \\
i \neq 1\end{array}$ & Male & $K$ & $x$ \\
$\begin{array}{l}S_{i} A_{\mathrm{h}} / S_{j} A_{\mathrm{h}} \quad \text { Hermaphrodite } \\
i \neq 1, j \neq 1, i \neq j\end{array}$ & 1 & $1-x$ \\
\hline
\end{tabular}

Table 1). In the model presented in this paper, we define the male advantage in fertility $(K)$ as the amount of pollen produced by a male divided by the amount of pollen produced by a hermaphrodite. Moreover, we assume that no fitness variation occurs within each sexual phenotype.

All of the different possible genotypes and their associated phenotypes, under the assumption of dominant female-sterility, are presented in Table 1(a), along with their relative male-fertilities and frequencies. The crossing table (Table 1b) among pollen donors and hermaphrodite recipients in generation $t$ gives the compatibility conditions for each cross, the frequency of compatible pollen genotypes and the genotypes produced in the next generation $(t+1)$. Not all the pollen types contribute to the next generation. Therefore, the frequency of a progeny genotype must be weighted by the frequency of compatible pollen over each hermaphrodite recipient. This allows the calculation of the male frequency in the generation $t+1\left(x^{\prime}\right)$, given in the following recursion equation:

$$
x^{\prime}=\frac{\frac{K x}{2}}{\left.\left.\frac{K x}{2}+\frac{n 3}{n 1}\right) \frac{K x}{2}+1 \quad x\right)}=\frac{\frac{K x}{2}}{\left.K x \frac{n 2}{n 1}\right)+\left(\begin{array}{ll}
1 & \left.x) \frac{n 3}{n 1}\right)
\end{array}\right.} .
$$

\section{Results}

\section{Dominant model}

The equilibrium male frequencies $\left(x_{\mathrm{eq}}\right)$ were easily found by solving the recursion eqn (2), for $x^{\prime}=x$. The solution of the resulting first-degree equation is given in the following equation:

$x_{\mathrm{eq}}=\frac{\left.K \frac{n}{n} \frac{1}{3}\right)}{2\left[\begin{array}{ll}\left.K \frac{n}{n} \frac{2}{3}\right) & 1\end{array}\right]}$

(b) Crossing table among pollen donors and hermaphrodite recipients

\begin{tabular}{lll}
\hline $\begin{array}{l}\text { Recipient genotype } \\
\text { frequency) }\end{array}$ & \multicolumn{2}{c}{$\begin{array}{c}\text { Pollen genotype } \\
\text { (frequency) }\end{array}$} \\
\hline $\begin{array}{l}S_{i} A_{\mathrm{h}} / S_{j} A_{\mathrm{h}} \\
(1)\end{array}$ & $\begin{array}{l}S_{1} A_{\mathrm{m}} \\
(K x / 2)^{*}\end{array}$ & $\begin{array}{l}S_{k} A_{\mathrm{h}} \\
\left(K x / 2^{*}+(1-x)^{* *}\right)\end{array}$ \\
Compatibility conditions & Always compatible & $k \neq i$ and $k \neq j$ \\
Compatibility probability & 1 & $1-2 /(n-1)=(n-3) /(n-1)$ \\
Progeny genotype & $S_{1} A_{\mathrm{m}} / S_{i} A_{\mathrm{h}}$ & $S_{i} A_{\mathrm{h}} / S_{k} A_{\mathrm{h}}$ \\
& $i \neq 1$ & $i \neq 1, k \neq 1, i \neq k$ \\
Progeny frequency & $(K x / 2) / W$ & $((K x / 2+(1-x))(n-3) /(n-1)) / W$ \\
\hline
\end{tabular}

* Pollen produced by male; ** pollen produced by hermaphrodite; $W$ : weighting factor because all pollen types do not contribute to the next generation.

(c) The Genetical Society of Great Britain, Heredity, 85, 413-422. 
This result looks very similar to the equilibrium frequency obtained by Lloyd (1975) and Charlesworth

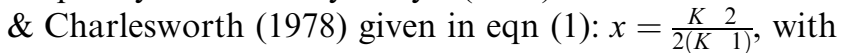
$K$ in the denominator replaced by $\left.K^{\prime}=K \frac{n 2}{n 3}\right)>K$ and in the numerator by $\left.K \frac{n}{n} \frac{1}{3}\right)$. Replacing $K$ with $K^{\prime}$ makes sense because the ratio $\frac{n 2}{n} 3$ ) $>1$ corresponds to the cross-compatibility advantage of males compared with hermaphrodites, as we shall demonstrate in the following paragraph.

The genotype of a male is $S_{1} A_{\mathrm{m}} / S_{i} A_{\mathrm{h}}(i \neq 1)$. Thus it produces half $S_{1} A_{\mathrm{m}}$ and half $S_{i} A_{\mathrm{h}}$ pollen. The genotype of a hermaphrodite is $S_{j} A_{\mathrm{h}} / S_{k} A_{\mathrm{h}}$ (with $j \neq k, j$ and $k \neq 1$; for instance $S_{2} A_{\mathrm{h}} / S_{3} A_{\mathrm{h}}$ ). $S_{1}$ pollen grains are always compatible with hermaphrodites, whereas $S_{i}$ pollen grains have a probability $\frac{n 3}{n 1}$ of being compatible: indeed, out of the $n-1$ possible alleles $(i=2 \ldots n)$, $n-3$ alleles are compatible $(i=4 \ldots n$ in our example). The mean probability that a pollen grain produced by a male will be compatible on a given stigma is thus:

$\frac{1}{2}+\frac{n \quad 3}{2(n-1)}=\frac{n \quad 2}{n \quad 1}$.

On the same stigma (say $S_{2} A_{\mathrm{h}} / S_{3} A_{\mathrm{h}}$ ), the mean probability that a pollen grain produced by a hermaphrodite will be compatible is $\frac{n 3}{n-1}$.

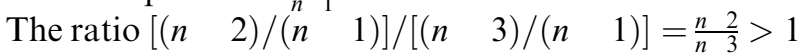
is thus the cross-compatibility advantage of males relative to hermaphrodites. Such a difference between males and hermaphrodites does not exist when $S_{1}$ alleles can be either associated with the $A_{\mathrm{h}}$ allele or with $A_{\mathrm{m}}$ allele: in this case, the equilibrium male frequency is the one obtained with the compensation model, corresponding to eqn (1). When the alleles $S_{1}$ and $A_{\mathrm{m}}$ are in complete linkage disequilibrium, the cross-compatibility advantage alone cannot account for the differences in male equilibrium frequency between our model and the compensation model. Taking into account just the cross-compatibility advantage would lead to the following male frequency:

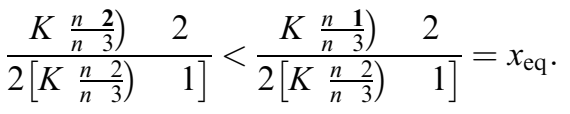

The difference from the numerator in eqn (3) (given here in $x_{\mathrm{eq}}$ ) and indicated in bold characters can be explained by comparing the recursion equation for $x$ obtained in our model (eqn 2), rewritten using $K^{\prime}=K \frac{n}{n} \frac{2}{3}$ ):

$x^{\prime}=\frac{1}{2}\left(\begin{array}{ll}\frac{n}{n} & 1\end{array}\right) \frac{K^{\prime} x}{K^{\prime} x+(1 \quad x)}$,

with the recursion equation corresponding to the compensation model: $x^{\prime}=\frac{1}{2} \frac{K^{\prime} x}{K^{\prime} x+(1 \quad x)}$.

Equation (5) gives the expected proportion of males $x^{\prime}$ in generation $t+1$, when males represent a fraction $x$ of the population at generation $t$, and produce $K^{\prime}$ more male gametes than hermaphrodites. The factor $1 / 2$ represents the fact that half of male offspring are males. In our model, this is no longer true. Males indeed produce half $\mathrm{S}_{1} \mathrm{~A}_{\mathrm{m}}$ gametes, and half $\mathrm{S}_{i} \mathrm{~A}_{\mathrm{h}}$ gametes. But on a given stigma, the probability of compatibility of $S_{i} A_{\mathrm{h}}$ pollen grains is only $\frac{n 3}{n} 1$. The mean proportion of offspring bearing allele $S_{1} A_{\mathrm{m}}$ which will be male is thus $\left.\left.\frac{1}{2} /\left[\begin{array}{lll}\frac{1}{2} \\ \frac{1}{2} \frac{n}{n} & 1\end{array}\right)\right]=\frac{1}{2} \frac{n}{n} \frac{1}{2}\right)$ which is greater than $1 / 2$.

The combined effects of the cross-compatibility advantage $\left.\left(K^{\prime}=K \frac{n}{n} \frac{2}{3}\right)>K\right)$ and of the biased sexratio in male offspring $\frac{1}{2} \frac{n 1}{n}$ ) $>\frac{1}{2}$ can lead to very high male frequencies (Fig. 1). For $n=3$, the male frequency reaches unity, leading to population extinction. For higher values of $n$, the male frequency is always higher than the value $(K-2) / 2(K-1)$ predicted by the compensation model with a simple nuclear sex determination (Fig. 1), although it approaches this limit for higher values of $n$. Recall that for low values of male advantage, $K$ (between 1 and 2, not shown), males cannot be maintained in the compensation model. In contrast, they can be maintained at rather higher frequencies using our model. For instance, with $K=1.5$ and with six self-incompatibility alleles, eqn (2) shows that $25 \%$ males can be maintained at equilibrium. This requires a much higher male advantage $(K=3)$ under

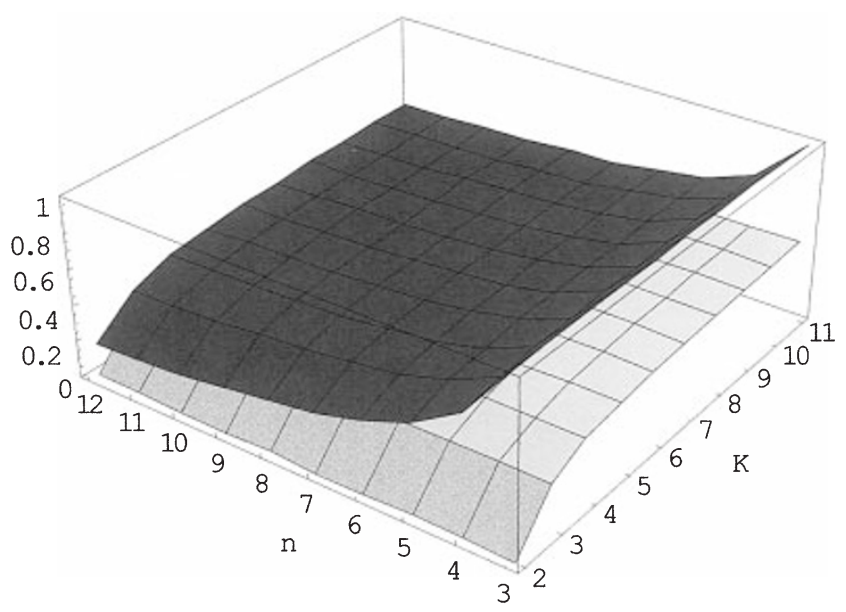

Fig. 1 Male frequency at equilibrium in our dominant model (upper nappe, eqn 2) and in the compensation model (lower nappe, eqn 1 ), as a function of the number of S-alleles ( $n$, from 3 to 12 ) and the relative male advantage in fertility ( $K$, from 2 to 11$)$. 
the compensation model (eqn 1). In our model, eqn (3) shows that the frequency of males is higher than 0.5 whenever $K>n-3$.

In this model, hermaphrodites are not simply cryptic females, because their pollen grains can fertilize the ovules of other hermaphrodites. For instance, when $K=2$ and $n=5$, there are $5 \times(5-1) / 2=10$ possible plant genotypes that are all heterozygous at the selfincompatibility locus (Table 2). Among these 10 genotypes, four bear the dominant female-sterility allele $\left(S_{1} A_{\mathrm{m}}\right)$ and one of the other alleles $\left(S_{2}, S_{3}, S_{4}\right.$ or $S_{5}$; see Table 2). Considering a given hermaphroditic genotype (say $S_{2} S_{3}$, see Table 3 ), the proportion of $S_{1} A_{\mathrm{m}}$ pollen grains that is compatible is 0.5 , which ensures that half of the progeny are males. Of the remaining $50 \%$ compatible pollen grains (non- $S_{1} A_{\mathrm{m}}$ ), half are produced by males, and half by five different types of hermaphrodites, which therefore function as true hermaphrodites and not cryptic females. In the compensation model, in a population with $50 \%$ males (as half of male offspring are males), there cannot be any true hermaphrodites because the latter do not contribute to the subsequent generation via male gametes. However, in our model, it is possible to observe a population made up of $50 \%$ males and 50\% hermaphrodites which all demonstrate a real male function. This is possible because of the biased sex ratio in the progeny of males (as shown above).

\section{Recessive model}

When assuming recessive female-sterility, it is not possible to solve the recursion equations for $x^{\prime}=x$ analytically to find the equilibrium frequency of males. We thus iterated the recursion equations numerically for various parameter sets (eqns A1, A2, A3 and A4) using MATHEMATICA v.3.0 software (Wolfram, 1996). Because the female-sterility allele is recessive, males can only be homozygotes for this allele, and the only possible genotype for males will be $S_{1} A_{\mathrm{m}} / S_{2} A_{\mathrm{m}}$ (Table A1a).

The equilibrium male frequency is in general smaller than in the compensation model, except for small $K$ and small $n$ (Fig. 2).

\section{Discussion}

Our model demonstrates that an incompatibility system completely linked with a sex determination locus causes a frequency-dependent selection, and can therefore favour rare alleles through male function. Thus, it may induce the spread of the female-sterility allele (rare) within a hermaphroditic population. Contrary to the results predicted by Lloyd (1975) and Charlesworth \& Charlesworth (1978), this model can explain male frequencies greater than 0.5 in a

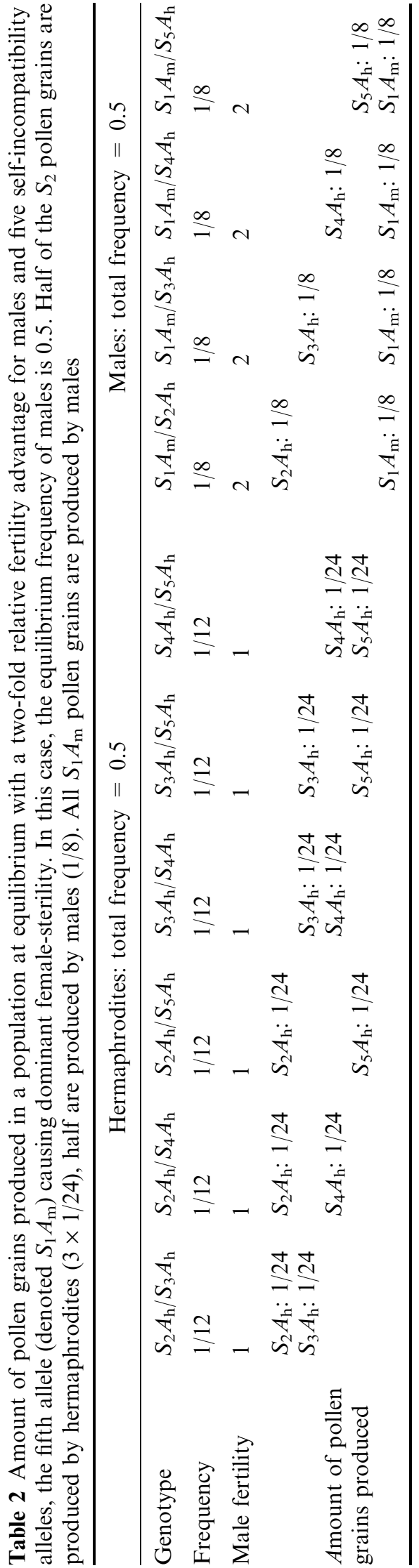


Table 3 What happens in an $S_{2} A_{\mathrm{h}} / S_{3} A_{\mathrm{h}}$ flower. Only $S_{4} A_{\mathrm{h}}, S_{5} A_{\mathrm{h}}$ and $S_{1} A_{\mathrm{m}}$ pollen grains germinate. Half of the ovules are fertilized by $S_{1} A_{\mathrm{m}}$ pollen grains, produced only by males. Half of the ovules are fertilized by $S_{4}$ or $S_{5}$ pollen grains, half of which are produced by males, and the remaining half by hermaphrodites, which are thus not cryptic females (even though the male proportion in the population is 0.5 ). Males thus contribute all $S_{1} A_{\mathrm{m}}$ alleles and $1 / 2$ of non- $S_{1} A_{\mathrm{m}}$ alleles, whereas hermaphrodites contribute $1 / 2$ of non- $S_{1} A_{\mathrm{m}}$ alleles

\begin{tabular}{lccccc}
\hline Pollen grains genotypes & $S_{2} A_{\mathrm{h}}$ & $S_{3} A_{\mathrm{h}}$ & $S_{4} A_{\mathrm{h}}$ & $S_{5} A_{\mathrm{h}}$ & $S_{1} A_{\mathrm{m}}$ \\
\hline Available amount issued from: & & & & & \\
$\quad$ Hermaphrodites & $1 / 2$ & $1 / 2$ & $1 / 2$ & $1 / 2$ & 0 \\
$\quad$ Males & $1 / 2$ & $1 / 2$ & $1 / 2$ & $1 / 2$ & 1 \\
Pollen grain fitness & 0 & 0 & 1 & 1 & 1 \\
Proportion of ovules sired & 0 & 0 & $1 / 4$ & $1 / 4$ & $1 / 2$ \\
Pollen-donors contribution & & & $1 / 8$ & $1 / 8$ & 0 \\
$\quad$ Hermaphrodites & & $1 / 8$ & $1 / 8$ & $1 / 2$ \\
$\quad$ Males & & & & \\
\hline
\end{tabular}

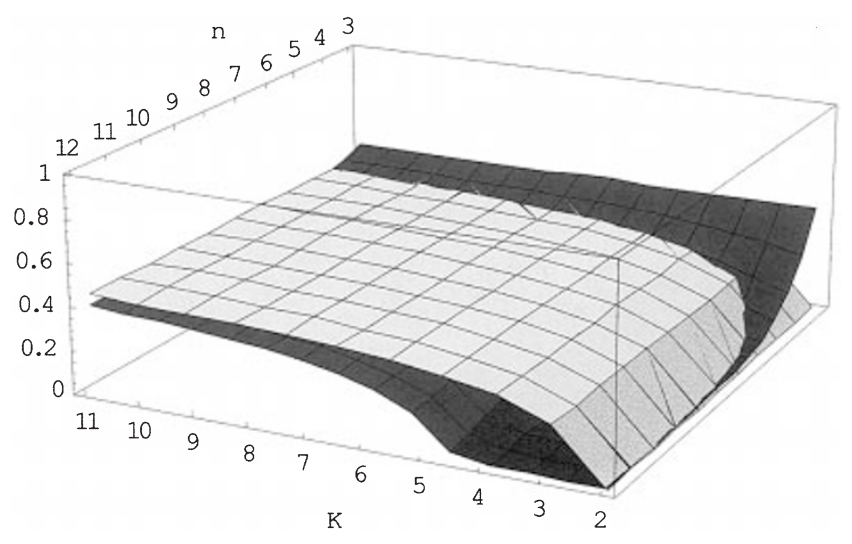

Fig. 2 Male frequency at equilibrium in our recessive model [lower nappe, obtained at equilibrium with eqns (A1)-(A4)] and in the compensation model (upper nappe, eqn 1), as a function of the number of $S$-alleles ( $n$, from 3 to 12) and the relative male advantage in fertility ( $K$, from 2 to 11$)$.

functionally androdioecious species. However, the equilibrium frequency of male phenotypes is highly dependent on three key parameters: the dominance of female-sterility at the sex locus, the number of alleles at the self-incompatibility locus, and the fitness advantage of the male morph.

In our dominant model, all $A_{\mathrm{m}}$ alleles are found in $S_{1} A_{\mathrm{m}}$ haplotypes, which is expected if the femalesterility mutation arises only once, and the $S_{1}$ allele is associated only with $A_{\mathrm{m}}$ : the $S_{1} A_{\mathrm{h}}$ haplotype does not exist. Two explanations would lead to this case. In the first explanation, when the female-sterility mutation first appears, $S_{1}$ alleles are as common as any other $S$ allele, and associated with the $A_{\mathrm{h}}$ allele in hermaphrodites. However, even if the $S_{1} A_{\mathrm{h}}$ haplotype is initially quite common, there is a selective process that reduces its frequency. As the $S_{1} A_{\mathrm{m}}$ male haplotype becomes common, as a result of the male advantage coupled with the compatibility advantage, the $S_{1}$ allele will be at a disadvantage in hermaphrodites. Through this selective process, $S_{1} A_{\mathrm{m}}$ frequency increases and the $S_{1} A_{\mathrm{h}}$ haplotype, although not completely eliminated at equilibrium (result not shown), may be eliminated in small populations by random drift, so that $S_{1}$ remains only in the $S_{1} A_{\mathrm{m}}$ haplotype. In the second explanation, when the female-sterility mutation first appears, this new allele, $A_{\mathrm{m}}$, has a pleiotropic effect on the self-incompatibility locus, which creates a new $S$-allele called $S_{1}$. This $S_{1}$ allele is then only associated with $A_{\mathrm{m}}$.

We chose to model a GSI rather than a sporophytic self-incompatibility for several reasons. First, GSI is more widespread than SSI in angiosperms (Charlesworth, 1985). Secondly, GSI is simpler to implement and thus ideal for an initial approach. Thirdly, GSI is the only system in which maleness can be associated with a single $S$-allele. In the SSI case, the female-sterile haplotype would never benefit from an absolute crosscompatibility advantage.

In our study, the results of models are highly dependent on the dominance relation at the sex locus. If female-sterility is dominant, a high frequency of males $(>50 \%)$ can be maintained within populations even when their advantage in fitness is low $(K \leq 2)$, as long as the number of $S$-alleles is also low $(n<6)$ (Fig. 1). On the other hand, if female-sterility is recessive, equilibrium male frequency is smaller than or equal to 0.5 (Fig. 2). When female-sterility is dominant, only one SI allele is associated with female-sterility $\left(S_{1} A_{\mathrm{m}}\right)$ and it is exclusively paternally inherited. This haplotype is more frequently transmitted than others because it benefits from (i) a cross-compatibility advantage 
$\frac{n 2}{n \frac{3}{3}}>1$ resulting from the allele $S_{1}$ [males are always compatible (fully or half-compatible) with all hermaphroditic genotypes]; (ii) a male-biased paternal sex ratio $\left.\frac{1}{2} \frac{n}{n} \frac{1}{2}\right)>\frac{1}{2}$ resulting from a greater cross-compatibility of male-determining alleles; and (iii) a male fitness advantage $(K)$. The first two phenomena are a result of the fact that males can interact with $n-1$ partners (different genotypes), whereas hermaphrodites have only $n-2$ possible partners. Consequently, a small $n$ causes a higher male advantage than a large $n$, and the former situation should be encountered more frequently in small, recently founded populations (colonization event). However, as the number of SI alleles (n) increases, incompatibility among hermaphrodites decreases and the male cross-compatibility advantage becomes negligible. This can occur through mutation or, more probably, migration from other populations, especially in wind-pollinated species such as Phillyrea, Fraxinus, and Mercurialis. Consequently, when $n$ is high, the difference in fitness between males and hermaphrodites depends only on their relative advantage in male fitness, and the equilibrium male frequency matches the results of the compensation model.

If female-sterility is recessive (see Appendix), the two male haplotypes $\left(S_{1} A_{\mathrm{m}}\right.$ and $\left.S_{2} A_{\mathrm{m}}\right)$ can be found in a heterozygous state in hermaphroditic individuals so that no haplotype is exclusively associated with males and paternally inherited. Consequently, males benefit from only a weak cross-compatibility advantage. Paradoxically, we find that the male advantage in fitness $(K)$ favours the frequency of hermaphrodites: as $K$ increases, the frequency of $S_{1} A_{\mathrm{m}}$ and $S_{2} A_{\mathrm{m}}$ haplotypes increases in the pollen pool, and providing that $n$ is large enough, more hermaphrodite phenotypes (heterozygotes for $S_{1} A_{\mathrm{m}}$ or $S_{2} A_{\mathrm{m}}$ haplotypes) will be produced than male phenotypes. Consequently, when female-sterility is recessive, the equilibrium male frequency is even smaller than in the compensation model for large values of $n$ and $K$ (Fig. 2). The genetics of sex determination has been studied in only two species; female-sterility is dominant in one species (Pannell, 1997b) and recessive in the other (Wolf et al., 1997). Therefore, it is not possible to draw any conclusion about the dominance of female-sterility.

The number of $S$-alleles $(n)$ that are maintained at mutation-selection equilibrium within a finite population depends on population size $N$ in a gametophytic self-incompatibility system (Wright, 1939; Vekemans \& Slatkin, 1994; Schierup, 1998; Vekemans et al., 1998), and may be less than six when $N<50$ (Vekemans \& Slatkin, 1994; Schierup, 1998). This small value of $n$ above which a high frequency of males cannot be maintained in our dominant model is thus plausible in small populations.
The linkage between the two loci is a key assumption in our model. Indeed, if the linkage between selfincompatibility and sex determination is not complete, our results coincide with those of the compensation model (results not shown). However, the recombinant haplotype for the $S$-allele originally associated with female-fertility $\left(S_{1} A_{\mathrm{h}}\right.$ in the dominant model), will have a higher probability of being lost by drift than the nonrecombinant male haplotype $\left(S_{1} A_{\mathrm{m}}\right)$, provided that $n$ is small enough (see above discussion).

The male haplotype $\left(S_{1} A_{\mathrm{m}}\right)$ can be regarded as a selfish gene, which favours its own transmission to the detriment of the others. Indeed, this exclusively paternally inherited haplotype not only suppresses the female function, but also biases the sex ratio of its own offspring and thus acts as a sex-ratio distorter. Selection acts on the haplotype as a whole, and so recombination between the two loci might be selected against. Such selfish haplotypes, implying two loci that never recombine (carried in an inversion loop, for example), have already been described (e.g. sex-ratio distorters; see review in Werren \& Beukeboom, 1998).

In this study, we have modelled the evolution of male frequency considering that androdioecy evolves from hermaphroditism, as in all previous theoretical studies (Lloyd's (1975), Charlesworth \& Charlesworth's (1978) phenotypic models as well as Pannell's (1997a) metapopulation genetic model). However, the only clear data favour androdioecy as a reversion from dioecy (Mercurialis annua, Pannell, 1997d). Because experimental data are so scarce, we still cannot reject the hypothesis of an evolution from hermaphrodism. Moreover, in the case of Phillyrea angustifolia, even if phylogenetic data (Wallander \& Albert 2000) do not provide a sufficient resolution to determine whether androdioecy evolved from dioecy or hermaphrodism, the presence of a relict pistil in male flowers, as the only significant morphological difference between male and hermaphrodite flowers (Lepart \& Dommée, 1992), strongly suggests that androdioecy has evolved from an hermaphrodite ancestor.

In conclusion, a gametophytic self-incompatibility system linked to a nuclear sex determinism, by causing a frequency-dependent selection, may explain the high frequencies of males recently reported in some androdioecious species (these include the functional androdioecious species P. angustifolia (Vassiliadis, 1999) and in two other potentially androdioecious species, Fraxinus lanuginosa (10-49.7\% males in populations) (Ishida \& Hiura, 1998) and Fraxinus ornus (50\% males in populations) (Dommée et al., 1999), for which the pollen of hermaphrodites has been proven potentially fertile). The conditions required by the model to explain the maintenance of high male frequency within a hermaphroditic 
population are dominance of female-sterility $\left(A_{\mathrm{m}}>A_{\mathrm{h}}\right)$ with a complete linkage between $A_{\mathrm{m}}$ and $S_{1}$ alleles, and a few $S$-alleles. Controlled crosses can easily test both predictions of this model.

\section{Acknowledgements}

We thank Xavier Vekemans, Carolyn R. Engel and Tean J. Mitchell for their suggestions on improving the manuscript, and two anonymous reviewers for their detailed critical reviews. The study was supported by C. Vassilidis.

\section{References}

AKIMOTO, J., FUKUHARA, T. AND KIKUZAWA, K. 1999. Sex ratios and genetic variation in a functionally androdioecious species, Schizopepon bryoniaefolius (Cucurbitaceae). Am. J. Bot., 86, 880-886.

ANDERSON, G. J. AND SYMON, D. E. 1989. Functional dioecy and andromonoecy in Solanum. Evolution, 43, 204-219.

CHARLESWORTH, B. AND CHARLESWORTH, D. 1978. A model for the evolution of dioecy and gynodioecy. Am. Nat., 112, 975-997.

CHARLESWORTH, D. 1984. Androdioecy and the evolution of dioecy. Biol. J. Linn. Soc., 23, 333-348.

CHARLESWORTH, D. 1985. Distribution of dioecy and selfincompatibility in angiosperms. In: Greenwood, P. J., Harvey, P. H. and Slatkin, M. (eds) Essays in Honour of John Maynard Smith, pp. 237-268. Cambridge University Press, Cambridge.

COUVET, D., BONNEMAison, F. AND GOUYON, P. H. 1986. The maintenance of females among hermaphrodites: the importance of nuclear-cytoplasmic interactions. Heredity, 57, 325-330.

COUVET, D., RONCE, O. AND GLIDDON, C. 1998. The maintenance of nucleocytoplasmic polymorphism in a metapopulation: the case of gynodioecy. Am. Nat., 152, 59-70.

COUVET, D., ATLAN, A., BELHASSEN, E., GLIDDON, C. J., GOUYON, P.-H. AND KJELlberG, F. 1990. Coevolution between two symbionts: the case of cytoplasmic male sterility in higher plants. Oxford Surv. Evol. Biol., 7, 225-249.

CUGUeN, J., WATtier, R., SAUMitou-laprade, P., FORCIOLI, D., MÖRCHEN, M., VAN DIJK, H. AND VERNET, P. 1994. Gynodioecy and mtDNA polymorphism in natural populations of the gynodioecious species Beta vulgaris ssp. maritima. Génét. Sél. Évol., 26, 87-101.

DELANNAY, X. 1978. La gynodioecie chez les angiospermes. Nat. Belges, 59, 223-235.

DOMMÉE, B., GUillerm, J. L. AND VALDEYRON, G. 1983. Régime de reproduction et hétérozygotie des populations de Thymus vulgaris L., dans une succession postculturale. C. r. Acad. Sci. Paris, 296, 111-114.

DOMMÉE, B., GESLOT, A., THOMPSON, J. D., REILlE, M. AND DENELle, N. 1999. Androdioecy in the entomophilous tree Fraxinus ornus (Oleaceae). New Phytol., 143, 419-426.
FRANK, S. A. 1989. The evolutionary dynamics of cytoplasmic male sterility. Am. Nat., 133, 345-376.

FRITSCH, P. AND RIESEBERG, L. H. 1992. High outcrossing rates maintain male and hermaphrodite individuals in populations of the flowering plant Datisca glomerata. Nature, 359, 633-636.

ISHIDA, K. AND HIURA, T. 1998. Pollen fertility and flowering phenology in an androdioecious tree, Fraxinus lanuginosa (Oleaceae), in Hokkaido, Japan. Int. J. Pl. Sci., 159, 941-947.

LEPART, J. AND DOMmÉE, B. 1992. Is Phillyrea angustifolia L. (Oleaceae) an androdioecious species? Bot. J. Linn. Soc., 108, 375-387.

LEWIS, D. 1941. Male-sterility in natural populations of hermaphrodite plants. New Phytol., 40, 56-63.

Liston, A., RIESEBERG, L. H. AND ELIAS, T. S. 1990. Functional androdioecy in the flowering plant Datisca glomerata. Nature, 343, 641-642.

LLOYD, D. G. 1975. The maintenance of gynodioecy and androdioecy in angiosperms. Genetica, 45, 325-339.

LLOYD, D. G. 1977. Genetic and phenotypic models of natural selection. J. Theor. Biol., 69, 543-560.

ORNDUFF, R. 1972. The breakdown of trimorphic incompatibility in Oxalis section Corniculatae. Evolution, 26, 52-65.

PANNELl, J. 1997a. The maintenance of gynodioecy and androdioecy in a metapopulation. Evolution, 51, 10-20.

PANNELL, J. 1997b. Mixed genetic and environmental sex determination in an androdioecious population of Mercurialis annua. Heredity, 78, 50-56.

PANNELL, J. 1997c. Variation in sex ratios and sex allocation in androdioecious Mercurialis annua. J. Ecol., 85, 57-69.

PANNELl, J. 1997d. Widespread functional androdioecy in Mercurialis annua L. (Euphorbiaceae). Biol. J. Linn. Soc., 61, 95-116.

RICHARDS, A. J. 1997. Plant Breeding Systems, 2nd edn. Chapman \& Hall, London.

SCHIERUP, M. H. 1998. The number of self-incompatibility alleles in a finite, subdivided population. Genetics, 149, 1153-1162.

vASSILIADIS, C. 1999. Evolution et maintien de l'androdioécie. Etude théorique et approches expérimentales chez Phillyrea angustifolia L. Ph.D. Thesis. Université des Sciences et Technologies de Lille, Lille.

VASSILIADIS, C., LEPART, J., SAUMITOU-LAPRADE, P. AND VERNET, P. 2000. Self-incompatibility and male fertilisation success in Phillyrea angustifolia (Oleaceae). Int. J. Pl. Sci., 161, 393-402.

veKEMANS, X. AND SLATKIN, M. 1994. Gene and allelic genealogies at a gametophytic self-incompatibility locus. Genetics, 137, 1157-1165.

VEKEMANS, X., SCHIERUP, M. H. AND CHRISTIANSEN, F. B. 1998. Mate availability and fecundity selection in multi-allelic selfincompatibility systems in plants. Evolution, 52, 19-29.

WAllander, E. AND ALBert, V. A. 2000. Phylogeny and classification of Oleaceae based on RPS16 and TRNL-F sequence data. Am. J. Bot., 87, 1827-1841.

WERREN, J. H. AND BEUKEBOOM, L. W. 1998. Sex determination, sex ratios, and genetic conflict. Ann. Rev. Ecol. Syst., 29, 233-261. 
WOLF, D. E., RIESEBERG, L. H. AND SPENCER, S. C. 1997. The genetic mechanism of sex determination in the androdioecious flowering plant, Datisca glomerata (Datiscaceae). Heredity, 78, 190-204.

wolfram, s. 1996. The Mathematica Book. Wolfram Media/ Cambridge University Press, Cambridge.

\section{Appendix: recessive female sterility}

If female-sterility is recessive $\left(A_{\mathrm{m}}<A_{\mathrm{h}}\right)$, males must be homozygous for this allele, which would never occur if only one SI allele is associated with the sterility allele. We thus assumed that two incompatibility alleles $\left(S_{1}\right.$ and $S_{2}$ ) are in complete linkage disequilibrium with the sterility allele $\left(A_{\mathrm{m}}\right)$. All other self-incompatibility alleles $\left(S_{3} \ldots S_{\mathrm{n}}\right)$ play the same role in the population for obvious symmetry reasons, and we will thus consider their frequencies to be identical.

A 'regular' pollen grain (neither $S_{1}$ nor $S_{2}$ ) will be incompatible if its incompatibility allele corresponds to one of the two alleles of the recipient which are different from each other, and both different from $S_{1}$ and $S_{2}$ (probability $=2 /(n-2))$. All other pollen genotypes are compatible with a probability of $1-(2 /(n-2))$ or $(n-4) /(n-2)$ (see Table A1). In addition, situations where a 'regular' pollen grain arrives on the stigma of a hermaphrodite bearing one $S$-allele associated with the female-sterility allele (i.e. $S_{1}$ or $S_{2}$ ), the other being any other $S$-allele must be considered. The compatibility probability in that case is $(n-3) /(n-2)$ (see Table A1).
WRIGHT, s. 1939. The distribution of self-sterility alleles in populations. Genetics, 24, 538-552.

YAMPOLSKY, C. AND YAMPOLSKY, H. 1922. Distribution of sex forms in the phanerogamic flora. Bibl. Genet., 3, 1-62.

The different genotypes of the individuals under this assumption, their associated phenotypes, relative male fertility, and frequencies are presented in Table A1(a). The frequency of compatibility of a pollen genotype with a hermaphrodite recipient $\mathrm{S}_{j} \mathrm{~A}_{\mathrm{h}} / \mathrm{S}_{k} \mathrm{~A}_{\mathrm{h}}(j \neq k, j$ and $k \neq 1$ ), and the phenotype of the progeny produced are shown in Table A1(b). This allows the calculation of the male frequency in generation $t+1\left(x^{\prime}\right)$, according to the four following recursion equations:

$$
\begin{aligned}
& x^{\prime}=\frac{y}{2 y+z}\left[\frac{K x+y}{\left.K x+y+2 \frac{n 3}{n} 2\right)(y+z)}\right] \\
& y^{\prime}=\frac{1}{2(2 y+z)}\left[y+\frac{z(K x+y)}{\left.K x+y+\frac{n 4}{n 2}\right)(y+z)}\right] \\
& t^{\prime}=y^{\prime} \\
& z^{\prime}=\frac{y+z}{2 y+z}\left[\frac{\left.2 y \frac{n 3}{n 2}\right)}{\left.K x+y+\frac{n 3}{n 2}\right)(y+z)}+\frac{\left.z \frac{n 4}{n 2}\right)}{\left.K x+y+\frac{n 4}{n 2}\right)(y+z)}\right]
\end{aligned}
$$

Table A1: Characteristics of crosses and progeny in the recessive model $\left(A_{\mathrm{h}}>A_{\mathrm{m}}\right)$ : two 'male' haplotypes are found $\left(\mathrm{S}_{1} \mathrm{~A}_{\mathrm{m}}\right.$ and $\left.\mathrm{S}_{2} \mathrm{~A}_{\mathrm{m}}\right)$ in the population which contains $n$ incompatibility alleles

(a) Genotypes and associated phenotypes, relative male fertility and frequencies of individuals (there must be at least three self-incompatibility alleles)

\begin{tabular}{lccc}
\hline Genotype & $\begin{array}{c}\text { Sexual } \\
\text { phenotype }\end{array}$ & $\begin{array}{c}\text { Relative male } \\
\text { fertility }\end{array}$ & $\begin{array}{c}\text { Frequency } \\
x+y+z+t=1\end{array}$ \\
\hline$S_{1} A_{\mathrm{m}} / S_{2} A_{\mathrm{m}}$ & Male & $K$ & $x$ \\
$S_{1} A_{\mathrm{m}} / S_{i} A_{\mathrm{h}}$ & Hermaphrodite & 1 & $y$ \\
$i \neq 1$ and 2 & Hermaphrodite & 1 & $t^{*}$ \\
$S_{2} A_{\mathrm{m}} / S_{i} A_{\mathrm{h}}$ & & $z$ \\
$i \neq 1$ and 2 & Hermaphrodite & 1 & \\
$S_{i} A_{\mathrm{h}} / S_{j} A_{\mathrm{h}}$ & & \\
$i$ and $j \neq 1$ and $2, i \neq j$ & & & \\
\hline
\end{tabular}

*For obvious reasons of symmetry, $t=y$. 
(b) Crossing table among pollen donors and hermaphrodite recipients

Recipient genotype

frequency

$S_{j} A_{\mathrm{h}} / S_{k} A_{\mathrm{h}}$

$z /(y+t+z)=z /(2 y+z)$

Compatibility conditions

Compatibility probability

Progeny genotype

Progeny frequency

$S_{1} A_{\mathrm{m}} / S_{j} A_{\mathrm{h}}$

(2) $y /(2 y+z)$

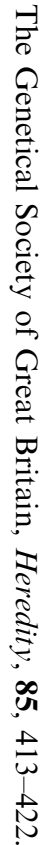

\section{Compatibility conditions}

Compatibility probability

Progeny genotype

Progeny frequency

$S_{2} A_{\mathrm{m}} / S_{j} A_{\mathrm{h}}$

$t /(2 y+z)$

\section{Compatibility conditions}

Compatibility probability

Progeny genotype

Progeny frequency
Pollen genotype frequency

\begin{tabular}{lll}
\hline$S_{1} A_{\mathrm{m}}$ & $S_{2} A_{\mathrm{m}}$ & $S_{i} A_{\mathrm{h}}$ \\
\hline$K x / 2^{*}+y / 2^{* *}$ & $K x / 2^{*}+t / 2^{* *}$ & $y / 2+t / 2+z^{* *}$ \\
Always compatible & Always compatible & $i \neq j$ and $i \neq k$ \\
1 & 1 & $(n-4) /(n-2)$ \\
$S_{1} A_{\mathrm{m}} / S_{i} A_{\mathrm{h}}$ & $S_{2} A_{\mathrm{m}} / S_{i} A_{\mathrm{h}}$ & $S_{i} A_{\mathrm{h}} / S_{j} A_{\mathrm{h}}$ and $S_{i} A_{\mathrm{h}} / S_{k} A_{\mathrm{h}}$ \\
$i \neq 1$ & $i \neq 2$ & $i \neq j$ and $k ; j \neq k ; i, j$ and $k \neq 1$ and 2 \\
$(K x+y) / 2 W$ & $(K x+t) / 2 W$ & {$[(z+(y+t) / 2)(n-4) /(n-2)] / W$}
\end{tabular}

\section{Incompatible}

0
Always compatible
$S_{2} A_{\mathrm{m}} / S_{j} A_{\mathrm{h}} \quad S_{1} A_{\mathrm{m}} / S_{2} A_{\mathrm{m}}$
$j \neq 1$ and 2

$(K x+t) / 2 W$

$i \neq 1$ and $i \neq j$

$(n-3) /(n-2)$

$S_{1} A_{\mathrm{m}} / S_{i} A_{\mathrm{h}} \quad S_{i} A_{\mathrm{h}} / S_{j} A_{\mathrm{h}}$

$i \neq 1$ and $2 i \neq j$

$[(z+(y+t) / 2)(n-3) /(n-2)] / W$

$\begin{array}{lll}\text { Always compatible } & \text { Incompatible } & \\ 1 & 0 & \begin{array}{l}i \neq j \text { and } i \neq 2 \\ (n-3) /(n-2)\end{array} \\ S_{2} A_{\mathrm{m}} / S_{i} A_{\mathrm{h}} \quad S_{1} A_{\mathrm{m}} / S_{2} A_{\mathrm{m}} & & S_{1} A_{\mathrm{m}} / S_{i} A_{\mathrm{h}} S_{i} A_{\mathrm{h}} / S_{j} A_{\mathrm{h}} \\ i \neq 1 \text { and } 2 & i \neq 1 \text { and } 2 ; i \neq j, i \text { and } j \neq 1 \text { and } 2 \\ (K x+y) / 2 W & {[(z+(y+t) / 2)(n-4) /(n-2)] / W}\end{array}$

